\title{
Description of outpatient utilization and costs in group of veterans with traumatic brain injury
}

\author{
Beeta Y. Homaifar, PhD; ${ }^{1-2 *}$ Jeri E. Harwood, PhD; ${ }^{3-4}$ Todd H. Wagner, PhD; ${ }^{5-6}$ Lisa A. Brenner, PhD ${ }^{1-2,7-8}$ \\ ${ }^{1}$ Department of Veterans Affairs (VA) Veterans Integrated Service Network 19, Mental Illness Research, Education and \\ Clinical Center, Denver, CO; Departments of ${ }^{2}$ Psychiatry and ${ }^{3}$ Pediatrics, University of Colorado Denver School of \\ Medicine (UCD SOM), Aurora, CO; ${ }^{4}$ Department of Biostatistics and Informatics, Colorado School of Public Health, \\ Aurora, CO; ${ }^{5}$ VA Palo Alto Health Care System, Palo Alto, CA; ${ }^{6}$ Stanford University, Stanford, CA; Departments of \\ ${ }^{7}$ Neurology and ${ }^{8}$ Physical Medicine and Rehabilitation, UCD SOM, Aurora, CO
}

\begin{abstract}
In an attempt to increase understanding regarding the nonacute healthcare needs of veterans with traumatic brain injury (TBI), we examined the outpatient utilization and cost patterns of 72 patients with TBI who were at least 4 years postinjury. We selected participants from a clinical database of veterans receiving care at a western Department of Veterans Affairs (VA) medical center. We extracted data from national utilization databases maintained by the VA and examined data from primary care and internal medicine, psychiatry and substance use, rehabilitation, and other services (e.g., ancillary, diagnostic, prosthetic, dental, nursing home, and home care). We extracted data for fiscal years 2002 to 2007. In addition to descriptive statistics, we modeled visits per year as a function of time since injury. The data show that this sample of patients with TBI consistently used a wide array of outpatient services over time with considerable variation in cost. Further study regarding economic aspects of care for patients with TBI is warranted.
\end{abstract}

Key words: aging, costs, Department of Veterans Affairs, healthcare, nonacute care, outpatient services, rehabilitation, traumatic brain injury, utilization, veterans.

\section{INTRODUCTION}

Planning for the healthcare needs of veterans with traumatic brain injury (TBI) is a difficult task that requires knowledge of short- and long-term outcomes. While a modest amount of information is available regarding the former, less is known about the long-term outcomes. Highlighting the need for research in this area is the number of TBIs sustained in the current military conflicts [1], as well as the growing population of individuals aging with TBI [2]. In an attempt to understand the nonacute healthcare needs of veterans with TBI, we examined the outpatient utilization and cost patterns of 72 patients with TBI who were at least 4 years postinjury. This descriptive study focuses on veterans who are beyond the acute phase of recovery.

The number of individuals with TBI is increasing, and social systems are grappling with how to support such individuals as they age [2]. Two-thirds of those who

Abbreviations: GCS = Glasgow Coma Scale, HERC $=$ Health Economics Resource Center, LOC $=$ loss of consciousness, PTA = posttraumatic amnesia, $\mathrm{TBI}=$ traumatic brain injury, VA = Department of Veterans Affairs, VAMC = VA medical center.

* Address all correspondence to Beeta Y. Homaifar, PhD; VA VISN 19 Mental Illness Research, Education and Clinical Center, 1055 Clermont Street, Denver, CO 80220; 303-3998020, ext 4237; fax: 303-370-7519.

Email: beeta.homaifar1@va.gov

DOI:10.1682/JRRD.2008.12.0166 
sustain a TBI before age 30 will likely live for another 30 to 40 years [2]. Lending support to this finding is research by Harrison-Felix et al., who demonstrated that sustaining a TBI resulted in only a 7-year reduction of life expectancy [3]. While the effects of aging with TBI are not yet clearly understood, research suggests the need for ongoing, long-term follow-up care.

Whereas a modest literature exists on the utilization and costs of acute TBI care [4-6], long-term follow-up data are scarce. Cifu et al. analyzed a group of individuals with moderate to severe TBI and found that half of all hospital admissions 3 years postinjury were for orthopedic surgery, reconstructive surgery, or both [7]. These surgeries were performed to reduce pain, enhance function, and improve appearance [7]. Of the hospitalizations for psychiatric purposes, the majority were for depression, while other reasons included behavioral dyscontrol and substance use [7]. At 5 years postinjury, hospitalization for orthopedic and reconstructive surgery declined while the use of specialized mental health care (e.g., psychiatric hospitalization) increased [8]. Hodgkinson et al. noted similar findings and found that patients with TBI who were 6 months to 4 years postinjury used services related to restoration of function, while those between 6 and 17 years postinjury used services related to life changes, such as the loss of a relationship or employment [9]. With regard to cost, most published data have been collected to understand the acute phase of care, and a strength of several such studies is that they have adjusted for severity of injury. One study found that costs increase as TBI severity increases [10], while another found an inverse relationship between cost and injury severity [11]. An early study determined that patients with moderate TBI required the most extensive and costly resources, postulating that the least injured did not require intensive services and the most severely injured did not survive long enough to consume extensive resources [12].

To date, literature focused on veterans has noted the importance of studying the economics of TBI. These studies have suggested strategies such as determining the most advantageous geographic placement of future Department of Veterans Affairs (VA) TBI treatment units, using telemedicine to meet the demand of TBIrelated services, and establishing a TBI database across the VA and Department of Defense that would allow researchers to study the effects of TBI severity and psychiatric comorbidities on healthcare utilization [13-15]. This article furthers research in this area by describing healthcare utilization and cost for veterans with TBI 4 to 40 years postinjury, taking into account age, years since injury, and severity of TBI.

\section{METHODS}

We selected participants from a clinical database of 408 veterans receiving care at a western VA medical center (VAMC). We confirmed history of TBI through chart reviews using criteria set forth by the Centers for Disease Control and Prevention [16]. We assessed injury severity (mild, moderate, or severe) by a continuing medical education program developed by the VA [17]. We used the following specific criteria: mild TBI-altered or loss of consciousness (LOC) of $<30$ minutes with negative imaging, Glasgow Coma Scale (GCS) of 13 to 15, or posttraumatic amnesia (PTA) of $<24$ hours; moderate TBI-LOC of $<6$ hours with positive imaging, GCS of 9 to 12 , or PTA of $<7$ days; and severe TBI-LOC $>6$ hours with abnormal imaging, GCS of $<9$, or PTA of $>7$ days [17].

Of this highly diverse group of 408 veterans, we excluded 12 who died and 73 who had neurologic disorders (e.g., stroke, anoxic brain injury, spinal cord injury, multiple sclerosis, Parkinson disease, Alzheimer disease) in addition to their history of TBI. Because we did not have access to non-VA healthcare utilization, we excluded patients with $<1 \mathrm{VA}$ visit of any type per year since the beginning of the VA electronic medical record system in 1998 (131 individuals). We also excluded patients $<4$ years postinjury (116 individuals) and patients who had multiple TBIs identified within the medical record (4 individuals). The remaining 72 veterans comprised the analytical sample.

For our sample, we extracted data from national utilization databases (National Patient Care Database and Patient Treatment Files) maintained by the VA. We used these databases to identify the outpatient clinic stop. We used the method created by Yu et al. [18] and Phibbs et al. [19] to categorize these codes into primary care and internal medicine, psychiatry and substance use, rehabilitation, and other services (e.g., ancillary, diagnostic, prosthetic, dental, nursing home, and home care). We used Health Economics Resource Center (HERC) Average Cost data instead of Decision Support System data; the two sources are highly correlated when annualized, and HERC provides an annualized data set that is easy to use [20]. We extracted data for fiscal years 2002 to 2007, 
resulting in a median of 6 years (range: 4-6) of data per patient. Although we extracted data from fiscal years 2002 to 2007, not all patients had 6 complete years of data (eight had 5 years of data and one had 4 years). The HERC Average Cost files provided the cost data [19], and we inflated all costs to 2007 dollars [21].

In addition to descriptive statistics, we used regression models to estimate the mean number of visits per year for 4 to 40 years since injury while controlling for age. For each of four categories of outpatient healthcare utilization (primary care and internal medicine, psychiatric and substance use, rehabilitation, and other services), we ran models for all patients $(n=68)$, for those with mild TBI only $(n=17)$, and for those with moderate or severe TBI $(n=51)$. The regressions did not include four patients with moderate TBI $>40$ years postinjury, as too few data points were available to estimate a stable mean. We assumed that the mean number of visits per year would vary smoothly over time since injury (i.e., on average, utilization would not change drastically year-toyear). Therefore, we performed a natural cubic B-spline transformation [22] of the variable "years since injury" and used this as a predictor in the regression models. This method smooths the raw data and allows for nonlinear trajectories. Additionally, to estimate the mean utilization at any time point, this method incorporates information from surrounding time points, which is consistent with the assumption of smoothly varying utilization.

\section{RESULTS}

Of the 72 veterans, 60 were service connected $(10 \%-100 \%)$ for various issues, including their history of brain injury. Sixteen veterans sustained their TBI during military service (between 1965 and 1993). Table 1 shows descriptive information for our sample. Most (76\%) of our sample had either a moderate or severe TBI. Almost all the veterans were male.

Table 2 shows the estimated annual outpatient visits. These patients with TBI used a wide array of services. Primary care and internal medicine use for those with mild TBI was higher than for those with moderate or severe TBI. For psychiatry and substance use services as well as rehabilitation, those with moderate or severe TBI had higher utilization than those with mild TBI. With the exception of patients 10 years postinjury, those with mild TBI used more "other" healthcare services than patients with moderate or severe TBI.

Within severity levels at 10 and 20 years postinjury, patients with mild TBI used more primary care and internal medicine than all other services (for example, at 10 years postinjury, 5.7 annual visits to primary care and internal medicine vs 1.4 psychiatry and substance abuse visits, 0.9 rehabilitation visits, and 4.9 other healthcare service visits). Beyond 20 years postinjury, those with mild TBI used more "other" healthcare services than the remaining three healthcare categories. Patients with moderate or severe TBI used more primary care and internal medicine than psychiatry and substance use or rehabilitation services with the exception of the 40 -year time point, when they used more psychiatry and substance use services than the remaining three healthcare categories. With regard to trends, all visits increased over time for patients with mild TBI, but the pattern for patients with moderate or severe TBI varied.

Table 3 shows outpatient costs to VA. In any given year, patients may have had visits or costs in just one category or in all four categories; therefore, not all sample size subtotals add to 72 . The average visit cost across the four categories ranged from $\$ 604$ to $\$ 1,800$. Notably, costs varied considerably.

Table 1.

Characteristics of veterans with traumatic brain injury (TBI) $\geq 4$ years postinjury, fiscal years 2002 to 2007 .

\begin{tabular}{|c|c|c|c|c|c|c|}
\hline \multirow[t]{2}{*}{ Characteristic } & \multicolumn{2}{|c|}{$\begin{array}{l}\text { All Subjects } \\
\quad(n=72)\end{array}$} & \multicolumn{2}{|l|}{$\begin{array}{l}\text { Mild TBI } \\
(n=17)\end{array}$} & \multicolumn{2}{|c|}{$\begin{array}{c}\text { Moderate/Severe TBI } \\
(n=55)\end{array}$} \\
\hline & Mean (Median) \pm SD & Range & Mean (Median) \pm SD & Range & Mean (Median) \pm SD & Range \\
\hline Years Since Injury ${ }^{*}$ & $18.4(15.0) \pm 12.2$ & $4-50$ & $19.7(17.0) \pm 10.9$ & $4-39$ & $18.0(13.0) \pm 12.7$ & $4-50$ \\
\hline Male (n) & 70 & - & 17 & - & 53 & - \\
\hline
\end{tabular}


Table 2.

Estimated mean number of outpatient visits per year and 95\% confidence intervals for veterans with traumatic brain injury (TBI) $\geq 4$ years postinjury, fiscal years 2002 to 2007.

\begin{tabular}{|c|c|c|c|}
\hline Healthcare Service & $\begin{array}{l}\text { Years Since } \\
\text { Injury }\end{array}$ & $\begin{array}{l}\text { Mild TBI } \\
(n=17)\end{array}$ & $\begin{array}{c}\text { Moderate/Severe TBI } \\
(n=51)\end{array}$ \\
\hline \multirow[t]{4}{*}{ Primary Care and Internal Medicine } & 10 & $5.7(3.2,9.7)$ & $4.3(3.3,5.5)$ \\
\hline & 20 & $8.2(5.8,11.6)$ & $6.7(5.2,8.6)$ \\
\hline & 30 & $11.7(7.6,17.7)$ & $6.2(4.4,8.6)$ \\
\hline & 40 & $16.5(8.4,31.4)$ & $4.4(2.0,8.7)$ \\
\hline \multirow[t]{3}{*}{ Psychiatry and Substance Use } & 10 & $1.4(0.4,3.2)$ & $4.1(2.4,6.8)$ \\
\hline & 30 & $2.9(0.9,7.2)$ & $3.3(1.7,5.7)$ \\
\hline & 40 & $4.0(0.6,14.2)$ & $5.9(1.8,16.1)$ \\
\hline Rehabilitation & $10-40^{\dagger}$ & $0.9(0.5,1.2)$ & $1.3(0.8,2.0)$ \\
\hline \multirow[t]{2}{*}{ Other ${ }^{\ddagger}$} & 10 & $4.9(3.2,7.2)$ & $5.8(4.3,7.7)$ \\
\hline & 20 & $8.1(6.1,10.7)$ & $5.7(4.6,7.1)$ \\
\hline
\end{tabular}

Figures 1 to $\mathbf{4}$ display graphs of all subjects' outpatient visits. We modeled visits per year as smooth functions of time since injury. This method provides meaningful estimates by smoothing the raw data, using surrounding information to estimate utilization at any one time point, and staying consistent with the assumption that, on average, utilization will vary smoothly over time since injury. There was generally consistent use of all outpatient services over time.

\section{DISCUSSION}

Despite considerable variation in cost, healthcare use among veterans in this sample remained relatively constant many years postinjury. Estimates indicate that for this cohort, primary care and internal medicine utilization increased from approximately three visits per year to approximately seven visits per year, remained constant for 10 years, and then tailed off slightly. Hodgkinson et al. found that their sample of patients with TBI also used approximately seven primary care visits during a 12-month time frame [9]. With the exception of the 10-year time point, patients with mild TBI used more visits (8.2-16.5) than the Hodgkinson et al. sample [9]. This difference may not be unusual because the prevalence of chronic medical and psychological conditions in veterans receiving care at VAMCs is much higher than in the general U.S. population [23]. Service connection and the use of automated pharmacy refills may also account for this difference. For the entire sample, the model estimated a constant mean utilization over time (10- to 40-year time points) of approximately four outpatient visits per year for psychiatry and substance use services and a constant mean of about two visits per year for rehabilitation services. Mean utilization of other healthcare services was estimated at approximately seven visits per year at 10 years postinjury, increasing to about nine visits per year at 40 years postinjury. No comparable published data exist with which to compare these findings.

Our results are descriptive but quite robust to outliers. Figures 1 to $\mathbf{4}$ show the mean visits per year from models using a B-spline method that assumes healthcare utilization will, on average, vary smoothly over time since injury and that is flexible enough to provide datadriven estimates. In all the analyses there were fluctuations over time, but use of services never tailed off completely.

Limitations to our study exist that warrant discussion. First, the data represent a single VAMC. Also, the final 
Table 3.

Outpatient costs for veterans with traumatic brain injury (TBI) $\geq 4$ years postinjury, fiscal years 2002 to 2007 (2007 dollars).

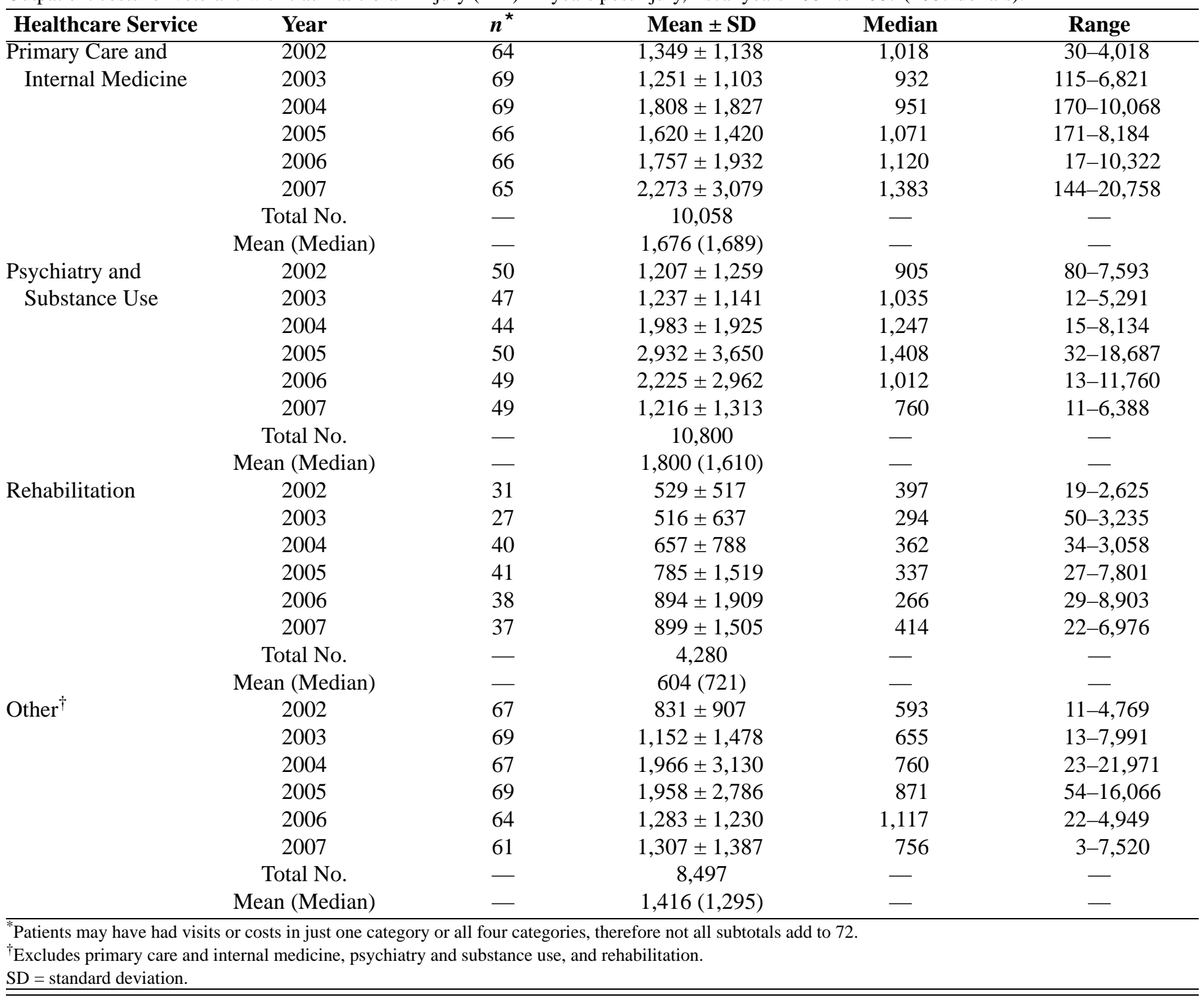

analytical sample comprised only 18 percent of the original sample of 408. Furthermore, some veterans sustained their injuries while in the military while others had civilianacquired injuries, further complicating generalizability. Patients with TBI who had one or more healthcare visits per year may be different than those who did not use services as frequently. Additionally, some veterans may have had other forms of insurance (Medicare, Medicaid, or employer-based), and we did not observe their non-VA healthcare use. Therefore, for our analytical group, we selected patients who consistently used VA providers (i.e., at least one visit of any type per year). This does not mean that they did not use non-VA providers, but we wanted to ensure that our conclusions reflected what we observed (i.e., VA utilization).

\section{CONCLUSIONS}

Little knowledge exists regarding utilization and cost of healthcare services by patients with TBI who are many years postinjury. In light of this, we demonstrated that, despite variability in cost, healthcare use remains relatively constant over time for this group of veterans. 


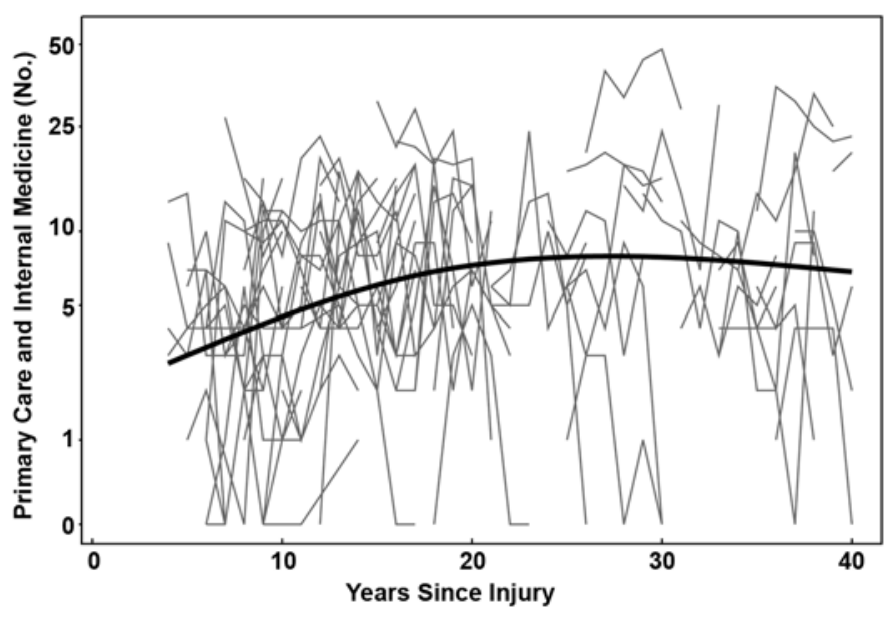

Figure 1.

Estimated mean number of primary care and internal medicine visits with raw data for veterans with traumatic brain injury, fiscal years 2002 to 2007.

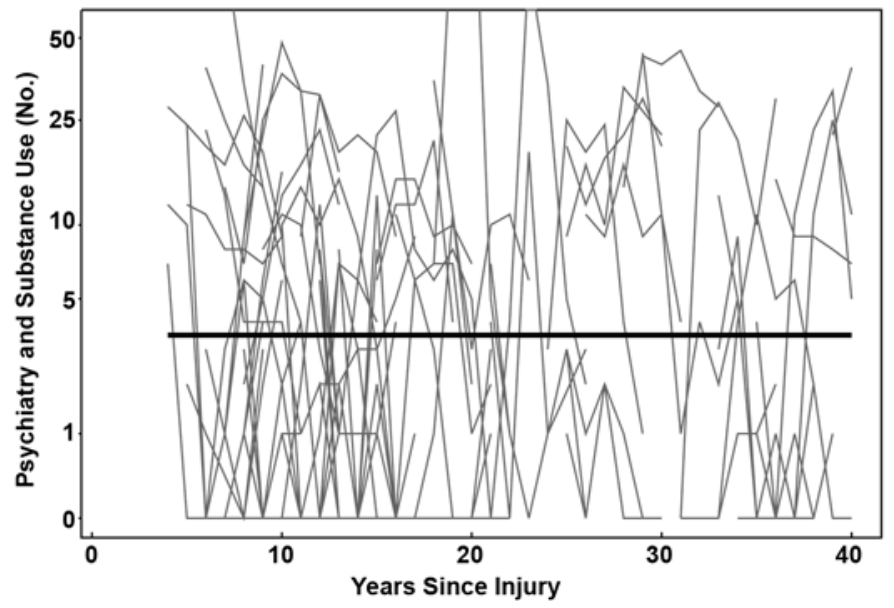

Figure 2.

Estimated mean number of psychiatry and substance use visits with raw data for veterans with traumatic brain injury, fiscal years 2002 to 2007.

While we can draw no conclusions regarding the marginal effect of TBI on utilization and cost of healthcare, this study offers data up to 40 years postinjury, filling a gap in the literature since the only other published study examining long-term utilization after TBI provided data up to 17 years postinjury [9]. Examining long-term healthcare utilization and associated costs allows VA healthcare professionals as well as those in administrative positions to plan for the sufficient allocation of financial and other resources for this group of patients. Future studies designed to longitudinally examine the

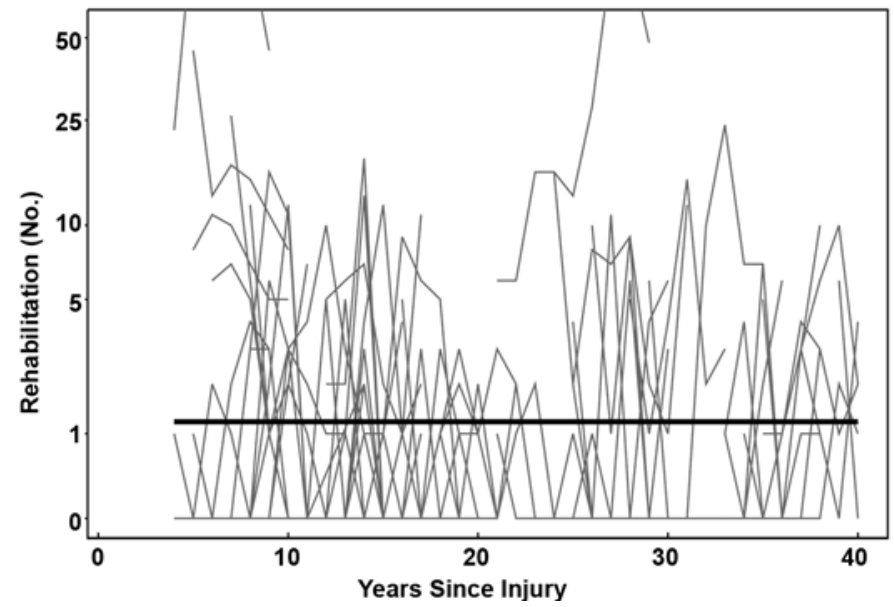

Figure 3.

Estimated mean number of rehabilitation visits with raw data for veterans with traumatic brain injury, fiscal years 2002 to 2007.

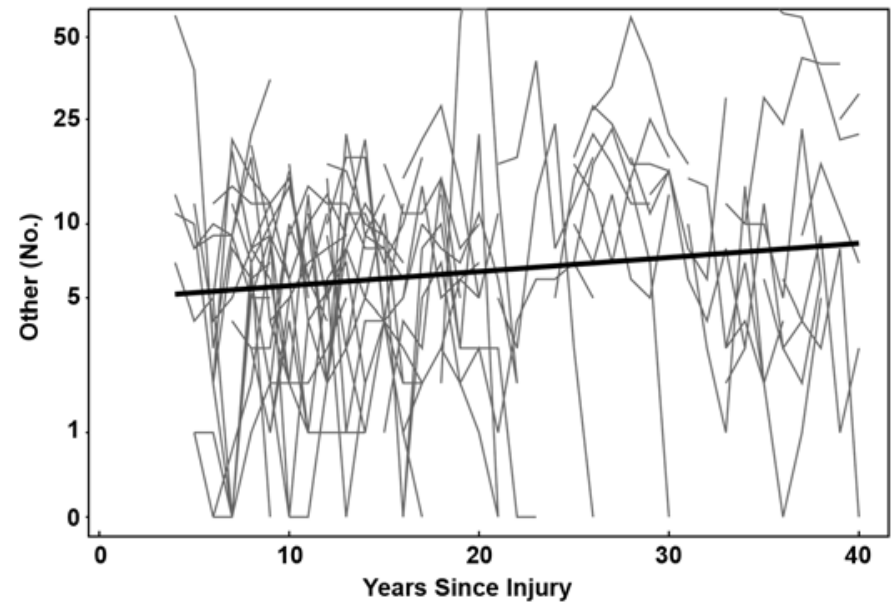

Figure 4.

Estimated mean number of visits for other healthcare services (not including primary care and internal medicine, psychiatry and substance use, and rehabilitation) with raw data for veterans with traumatic brain injury, fiscal years 2002 to 2007.

patterns and trajectories of utilization and cost for this growing group of individuals are warranted.

\section{ACKNOWLEDGMENTS}

\section{Author Contributions:}

Study concept and design: B. Y. Homaifar, J. E. Harwood, T. H. Wagner, L. A. Brenner.

Acquisition, analysis, and interpretation of data: B. Y. Homaifar, J. E. Harwood, T. H. Wagner, L. A. Brenner. 
Drafting of manuscript: B. Y. Homaifar, J. E. Harwood, T. H. Wagner, L. A. Brenner.

Critical revision of manuscript for important intellectual content:

B. Y. Homaifar, J. E. Harwood, T. H. Wagner, L. A. Brenner.

Statistical analysis: J. E. Harwood.

Study supervision: B. Y. Homaifar, L. A. Brenner.

Financial Disclosures: The authors have declared that no competing interests exist.

Funding/Support: This work was supported by the VA Veterans Integrated Service Network 19 Mental Illness Research, Education and Clinical Center.

Additional Contributions: The views expressed in this article are those of the authors and do not necessarily represent the views of the VA.

Participant Follow-Up: The authors do not plan to inform the participants of the publication of this study because it was an archival study and no contact information was collected.

\section{REFERENCES}

1. Warden D. Military TBI during the Iraq and Afghanistan wars. J Head Trauma Rehabil. 2006;21(5):398-402. [PMID: 16983225] DOI:10.1097/00001199-200609000-00004

2. Felicetti T, Trudel T, Mozzoni M. Health, aging and traumatic brain injury: Four years of investigation. Lippincotts Case Manag. 2005;10(5):264-65. [PMID: 16205210]

3. Harrison-Felix C, Whiteneck G, DeVivo M, Hammond FM, Jha A. Mortality following rehabilitation in the traumatic brain injury model systems of care. NeuroRehabilitation. 2004;19(1):45-54. [PMID: 14988587]

4. Fakhry SM, Trask AL, Waller MA, Watts DD; IRTC Neurotrauma Task Force. Management of brain-injured patients by an evidence-based medicine protocol improves outcomes and decreases hospital charges. J Trauma. 2004;56(3):492-500. [PMID: 15128118] DOI:10.1097/01.TA.0000115650.07193.66

5. Mayer NH, Pelensky J, Whyte J, Fidler-Sheppard R. Characterization and correlates of medical and rehabilitation charges for traumatic brain injury during acute rehabilitation hospitalization. Arch Phys Med Rehabil. 2003;84(2):242-48. [PMID: 12601656] DOI:10.1053/apmr.2003.50101

6. Wagner AK, Fabio T, Zafonte RD, Goldberg G, Marion DW, Peitzman AB. Physical medicine and rehabilitation consultation: Relationships with acute functional outcome, length of stay, and discharge planning after traumatic brain injury. Am J Phys Med Rehabil. 2003;82(7):526-36. [PMID: 12819540] DOI:10.1097/00002060-200307000-00006
7. Cifu DX, Kreutzer JS, Marwitz JH, Miller M, Hsu GM, Seel RT, Englander J, High WM Jr, Zafonte R. Etiology and incidence of rehospitalization after traumatic brain injury: A multicenter analysis. Arch Phys Med Rehabil. 1999;80(1):85-90. [PMID: 9915377] DOI:10.1016/S0003-9993(99)90312-X

8. Marwitz JH, Cifu DX, Englander J, High WM Jr. A multicenter analysis of rehospitalizations five years after brain injury. J Head Trauma Rehabil. 2001;16(4):307-17.

[PMID: 11461654]

DOI:10.1097/00001199-200108000-00002

9. Hodgkinson A, Veerabangsa A, Drane D, McCluskey A. Service utilization following traumatic brain injury. J Head Trauma Rehabil. 2000;15(6):1208-26. [PMID: 11056404] DOI:10.1097/00001199-200012000-00003

10. McGarry LJ, Thompson D, Millham FH, Cowell L, Snyder PJ, Lenderking WR, Weinstein MC. Outcomes and costs of acute treatment of traumatic brain injury. J Trauma. 2002; 53(6):1152-59. [PMID: 12478043] DOI:10.1097/00005373-200212000-00020

11. Vangel SJ Jr, Rapport LJ, Hanks RA, Black KL. Long-term medical care utilization and costs among traumatic brain injury survivors. Am J Phys Med Rehabil. 2005;84(3):153-60. [PMID: 15725788] DOI:10.1097/01.PHM.0000154896.55045.E7

12. Saywell RM Jr, Woods JR, Rappaport SA, Allen TL. The value of age and severity as predictors of costs in geriatric head trauma patients. J Am Geriatr Soc. 1989;37(7):625-30. [PMID: 2738282]

13. Côté MJ, Syam SS, Vogel WB, Cowper DC. A mixed integer programming model to locate traumatic brain injury treatment units in the Department of Veterans Affairs: A case study. Health Care Manag Sci. 2007;10(3):253-67. [PMID: 17695136] DOI:10.1007/s10729-007-9018-7

14. Girard P. Military and VA telemedicine systems for patients with traumatic brain injury. J Rehabil Res Dev. 2007;44(7): 1017-26. [PMID: 18075958] DOI:10.1682/JRRD.2006.12.0174

15. Lew HL, Cifu DX, Sigford B, Scott S, Sayer N, Jaffee MS. Team approach to diagnosis and management of traumatic brain injury and its comorbidities. J Rehabil Res Dev. 2007; 44(7):vii-xi. [PMID: 18075945]

16. Thurman DJ, Sniezek JE, Johnson D, Greenspan A, Smith SM. Guidelines for surveillance of central nervous system injury. Atlanta (GA): Centers for Disease Control and Prevention; 1995. 
17. Traumatic brain injury: A continuing medical education program. Washington (DC): Department of Veterans Affairs; 2004. Catalogue \#: SP VET-EES-A138.

18. Yu W, Wagner TH, Chen S, Barnett PG. Average cost of VA rehabilitation, mental health, and long-term hospital stays. Med Care Res Rev. 2003;60(3 Suppl):40S-53S. [PMID: 15095545]

19. Phibbs CS, Bhandari A, Yu W, Barnett PG. Estimating the costs of VA ambulatory care. Med Care Res Rev. 2003; 60(3 Suppl):54S-73S. [PMID: 15095546] DOI:10.1177/1077558703256725

20. Chapko MK, Liu CF, Perkins M, Li YF, Fortney JC, Maciejewski ML. Equivalence of two healthcare costing methods: Bottom-up and top-down. Health Econ. 2009; 18(10):1188-1201. [PMID: 19097041]

DOI:10.1002/hec.1422
21. Bureau of Labor Statistics. Consumer price index [Internet]. Washington (DC): U.S. Department of Labor; [cited 2009 Sep 16]. Available from: http://www.bls.gov/cpi/cpid07av.pdf.

22. Liang H, Wu H, Carroll RJ. The relationship between virologic and immunologic responses in AIDS clinical research using mixed-effects varying-coefficient models with measurement error. Biostatistics. 2003;4(2):297-312.

[PMID: 12925523]

DOI:10.1093/biostatistics/4.2.297

23. Yu W, Ravelo A, Wagner TH, Phibbs CS, Bhandari A, Chen S, Barnett PG. Prevalence and cost of chronic conditions in the VA health care system. Med Care Res Rev. 2003;60(3 Suppl):146S-67S. [PMID: 15095551] DOI: $10.1177 / 1077558703257000$

Submitted for publication December 23, 2008. Accepted in revised form May 28, 2009. 